\title{
Phonemic Status of Bangla Nasal Vowels: A Corpus Study
}

\author{
Md. Jahurul ISLAM
}

Georgetown University, United States

jahirju30@gmail.com

\begin{abstract}
This study investigated the phonemic status of the nasal vowels in Bangla (aka Bengali). It has been claimed for decades that all the seven monophthongal oral vowels in Bangla have phonemically contrastive nasal counterparts; however, an in-depth investigation of the status of nasality for all the vowels is lacking in the current literature. With a phoneme dictionary build from a text corpus of 8 (eight) million word-tokens and about 275 thousand word-types, this study investigated whether all the oral vowels have phonemically contrastive nasal vowels. Findings revealed that only five of the seven monophthongal vowels form phonemically contrastive relationships with their nasal counterparts; nasality in /æ/ and / / are not contrastive phonemically.
\end{abstract}

Keywords: nasal vowels; phonemic status; text corpus; Bangla/Bengali

\section{Povzetek}

Članek preučuje fonemski status nosnih samoglasnikov v bengalščini (dialekt aka). Skozi desetletja je prevladovalo mnenje, da ima $v$ bengalščini vseh sedem enostavnih samoglasnikov fonemsko kontrastivni nosni par, vendar pa to mnenje ni bilo podprto s poglobljenimi raziskavami. S pomočjo fonemskega slovarja, ki je bil zgrajen iz besedilnega korpusa z 8 milijoni pojavnic - od tega je približno 275 tisoč različnic - smo preverili, ali imajo vsi osnovni enostavni samoglasniki tudi svoje fonemsko kontrastivne nosne pare. Rezultati nakazujejo, da je takšnih parov v kontrastivni distribuciji samo 5 in da nosna /æ/ and / / nista fonemsko kontrastivna.

Ključne besede: nosni samoglasniki; fonemski status; besedilni korpus; bengalščina

\section{Introduction}

Bangla has been widely described to have a seven-vowel system, and nasality in those vowels have been argued to provide an additional set of phonemically contrastive vowels (Morshed, 1972; Alam, Habib \& Khan, 2008; Thompson, 2012). Thus, the seven monophthong vowels /i, e, æ, a, J, o, u/ have been argued to create contrast with their nasal counterparts $/ \tilde{\mathrm{i}}, \tilde{\mathrm{e}}, \tilde{\mathfrak{a}}, \tilde{a}, \tilde{\jmath}, \tilde{o}, \tilde{u} /$. All the previous accounts of vowel nasality in 
Bangla, however, relied on impressionistic judgment only, and the claim has not been directly and seriously addressed with sufficient and objective data in earlier literature. This study attempts to address the issue of the phonemic status of Bangla nasal vowels with more objective and quantifiable data to better understand the contribution of nasality in phonemic vowel contrasts in Bangla.

\section{Background}

\subsection{Bangla (oral) vowel system}

Bangla has a symmetric system of seven vowels. Morshed (1972) listed the vowels as /i, u, e, o, æ, o, a/: two high, two high-mid, two low-mid, and one low vowel (Figure 1). In terms of backness, there are front vs. backness contrasts except for the low one.

\begin{tabular}{lccc}
\hline & Front & Central & Back \\
\hline High & $\mathrm{i}$ & & $\mathrm{u}$ \\
\hline High-mid & $\mathrm{e}$ & & $\mathrm{o}$ \\
\hline Low-mid & $æ$ & & J \\
\hline Low & \multicolumn{2}{c}{$\mathrm{a}$} \\
\hline
\end{tabular}

Figure 1: Bangla vowels (Morshed, 1972, p. 24)

Shamim (2011) investigated the vowel contrasts in terms of phonological features and reported the same number of vowels, though with a subtle difference. He used the symbol / $\varepsilon /$ for the owel /æ/ in Morshed (1972); he calls it a "non-low" ([-low] vowel while /æ/ vowel has often been described as [+low] (Zsiga, 2013: p. 270)). The use of $/ \varepsilon /$ instead of $/ æ /$ provides an advantage to Shamim's proposal that the contrast between $/ e /$ and $/ \varepsilon /$ should be captured by means of the $[ \pm$ ATR] feature and not the [low] feature where /e/ is [+ATR] and / $\varepsilon /[-A T R]$. This way, the front vowel pair /e/-/ $/ \varepsilon /$ and the back vowel pair $/ 0 /-/ \mathrm{J} /$ creates a symmetric pattern where both the contrasts are achieved with the $[ \pm A T R]$ feature. Figure 2 provides the chart he used to represent all the seven Bangla vowels. 


\begin{tabular}{|lccccccc}
\hline & i & e & $\varepsilon$ & u & o & ว & a \\
high & + & - & - & + & - & - & - \\
low & - & - & - & - & - & - & + \\
ATR & + & + & - & + & + & - & - \\
round & - & - & - & + & + & + & - \\
back & - & - & - & + & + & + & + \\
\hline
\end{tabular}

Figure 2: Bangla vowels and phonological features

(Shamim, 2011, p. 8)

While the vowel descriptions in Morshed (1972) and Shamim (2011) were primarily based on native speaker intuition or impressionistic observation, Alam, Habib, and Khan (2008) investigates the acoustic properties of Bangla vowels and reported the same seven vowels. Figure 3 presents the first two formant frequencies of the vowels ( $F 1$ on $\mathrm{Y}$-axis and F2 on X-axis). The IPA symbols in the figure represent mean F1 and F2 values for the vowel categories; the corresponding Bangla vowel grapheme is to the left of the IPA symbols. The acoustic space also indicates to a symmetric vowels space for Bangla. The figure also includes the formant frequencies of the nasal vowel, which appear to be crease a similar symmetric vowel space like the oral vowels.

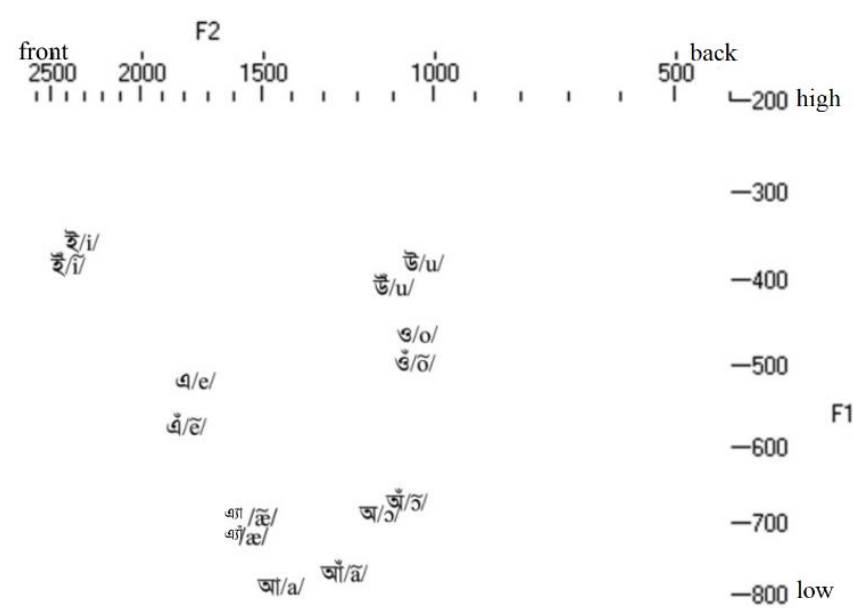

Figure 3: Bangla vowels and acoustic space (with nasals) (Alam et al., 2008, p. 9)

\subsection{Nasal vowels in Bangla}

That all the seven Bangla oral vowels have their phonemically contrastive nasal counterparts has been widely reported in earlier literature (Morshed, 1972; Alam et al., 2008; Barman, 2011; Thompson, 2012; Basu, Basu, Mitra, \& Mandal, 2009; Shamim, 
2011; Huq, 2002; Sarkar, 2004; Khan, 2008). As Morshed (1972) described, “... the number of nasalized vowels [in SCB] is equal to that of their oral counterparts, though the frequency of occurrence of nasalized vowels is far less than that of oral vowels" ( $p$. 62). Thus, in Morshed's terms, each of the oral vowels is phonemically contrastive with its oral counterpart. Therefore, he presented two groups of vowels in Bangla: oral and nasal, as shown in Table 1.

Table 1: Oral vs. nasal vowels in SCB (Morshed, 1972)

\begin{tabular}{cc}
\hline Oral vowels & Nasal vowels \\
\hline$/ \mathrm{i} /$ & $/ \tilde{\mathrm{I}} /$ \\
/e/ & $/ \tilde{e} /$ \\
/æ/ & $/ \tilde{æ} /$ \\
$/ \mathrm{a} /$ & $/ \tilde{a} /$ \\
$/ \mathrm{\jmath} /$ & $/ \tilde{\mathrm{o}} /$ \\
/o/ & $/ \tilde{o} /$ \\
$/ \mathrm{u} /$ & $/ \tilde{\mathrm{u}} /$
\end{tabular}

Khan (2008) also made similar claims that all the Bangla oral vowels have their nasal counterparts; however, he indicated that this might be true to some specific dialects only. In his words, "Bengali has seven vowels in its inventory /i, e, æ, a, o, o, u/," along with "seven nasal vowels for dialects that have contrastive nasalization" ( $p$. 25).

In Barman's (2011) account, "In Bangla, any [oral] vowel may be nasalized. Therefore, all the seven pure vowels in Bangla have their nasalized counterparts" ( $p$. 21). He cites the following words as the evidence of vowel nasality in Bangla (Table 2).

Table 2: Words with nasal vowels (Barman, 2011, p. 21)

\begin{tabular}{|c|c|c|}
\hline Nasal vowel & Word & Gloss \\
\hline /ã/ & /țãd/ & moon \\
\hline$/ \tilde{I} /$ & /ĩdur/ & rat \\
\hline /ẽ/ & /pẽt]a/ & owl \\
\hline /õ/ & /dnõa/ & smoke \\
\hline /ũ/ & /ũtsu/ & high \\
\hline /र̃ / & /pñt]a/ & rotten \\
\hline 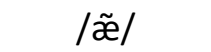 & /pãts/ & complexity \\
\hline
\end{tabular}

Note: Barman (2011) used /a/ and / $\mathrm{b} /$ instead of /a/ and /J/, respectively 
Thompson (2012) presented some minimal pairs to illustrate the scenario in more detail (Table 3). Reports of true minimal pairs, in fact, can provide concrete evidence that the oral-nasal pairs are phonologically contrastive. Unfortunately, most of the earlier studies did not include minimal pairs into the scene, whereas Thompson provided evidence for two Bangla vowels: /o/ and /a/.

Table 3: Oral-nasal minimal pairs (Thompson, 2012, p. 15)

\begin{tabular}{|c|c|c|c|}
\hline Nasal & Gloss & Oral & Gloss \\
\hline /bõti/ & curved knife & /boti/ & pill \\
\hline /gã/ & village & /ga/ & body \\
\hline /kãta/ & thorn & /kata/ & to cut \\
\hline /bãdnda/ & bind & /badha/ & obstruction \\
\hline /ãta/ & fix, stitch & /ata/ & flour \\
\hline /knãra/ & sword & $/ k^{h} a r a /$ & erect \\
\hline /kãda/ & weep & /kada/ & clay \\
\hline /kãtJa/ & unripe, green & /katja/ & wash \\
\hline
\end{tabular}

The claims made in earlier literature, as reviewed above, regarding the status of Bangla nasal vowels can indicate two distinct possibilities. First, as most studies claimed, Bangla has a total of fourteen distinctive phonologically contrastive monophthongs, where all the nasal vowels also enjoy equal status as separate phonemes along with the oral vowels. The problem with this assumption is that there has not been any direct attempt to verify this claim with data from Bangla; the claims in earlier studies were based on impressionistic judgments only. Only Thompson's (2012) description included some minimal pairs based on nasality (as presented in Table 3). Even this description presented evidence only for two of the vowels (/o/ and /a/) and not others. Therefore, in the absence of minimal pairs or near-minimal pairs in earlier literature, it is hard to determine if all the nasal vowels are indeed in phonemically contrastive status, and not merely some phonetic variations of the oral vowels.

The second possibility is that not all the seven nasal vowels are phonemically contrastive in Bangla. It could be possible that nasality in some of the oral vowels is determined lexically or by the phonetic contexts. It might be possible that some of the nasal vowels are phonetic variants of their oral counterparts.

\section{Methods}

To determine if a segment is phonemic in a given language or not, a reliable way is to find minimal pairs or near-minimal pairs based on the target segment. As Kennedy (2017) put forward, "Minimal and near-minimal pairs are convenient tools for us to 
discover contrastive oppositions" (p. 117). Kennedy defines a minimal pair as "a pair of words that differ at the surface just by a single phoneme;" he calls the used of minimal pairs as "a convenient shortcut to identify phonemes within languages" (p. 95). For example, the English minimal pair [pit - pet] "pit-pet" indicates that /i/ and /e/ are phonemically contrastive, and so they belong to two separate phonemes. On the other hand, near-minimal pairs are described as "forms that illustrate a phonemic contrast by virtue of containing different segments in equivalent immediate contexts" (Kennedy, 2017, p. 97). For example, Finnish words [ratas] "wheel" and [radan] "of a track" are not minimal pairs because there differ on more than one segments. The status of [t] and [d] here can be contrastive since they both occur in the same environment: [a_a] (full data in Kennedy, 2017, p. 96).

This study attempted to use minimal and near-minimal pairs to investigate whether all the nasal vowels in Bangla are contrastive with their oral counterparts. As the source of data, the study used a corpus of Bangla written text containing about 18 million word-tokens which had nearly 400 thousand word-types. Written text was preferred over any speech data due to several reasons. First, a spoken corpus takes a significant time and resource to build, along with the necessary coding of the necessary parameters. A text corpus is considerably easier to build and access. Secondly, the variety of lexicon is usually lower in a speech corpus; it is hard to ensure all possible word-types in speech (since corpus building usually happens in experimental settings which does not permit much flexibility in terms of experiment length). But, accumulating a big text corpus is somewhat easier (written texts of many languages are produced daily in large quantity, and are often freely available).

A text corpus was deemed suitable for the purpose of phonemic investigation in this study because Bangla orthography mostly corresponds to the spoken form, which is not the case for many other languages, e.g., English. The same approach would not be suitable for English due to extreme lack or correspondence between graphemes and phonemes; in such cases, a carefully built phonemic dictionary, as the CMU dictionary (CMU, 2018) would be necessary. Since most Bangla graphemes are tied in one-to-one relation with the corresponding phonemes, use of a text corpus was deemed suitable for this study. (Of course, Bangla still has some exceptions to the one-to-one correspondence in some cases including complex consonants and inherent vowels; Section 3.2 details of how these issues were handled.)

\subsection{Corpus}

The corpus used in this study was first developed and used by Arafat, Islam, and Khan (2006) who called it "Prothom Alo Corpus." The corpus consisted of a collection of the text published in the Bangla daily Prothom Alo (which is often considered to be the most widely read Bangla newspaper in Bangladesh). As Arafat et al. (2006) described, the Prothom Alo was chosen for building the corpus because this newspaper was the 
"one with less spelling mistakes and with conventional spelling of Bangla words" (p. 2). The corpus consisted of about 18 million word-tokens and 400 thousand word-types. For this study, a subset of the main corpus was used, and it contained about 8 million word-tokens and 275 thousand word-types.

\subsection{Data processing}

Even though most graphemes in Bangla map to corresponding phonemes consistently, there were some exceptions which needed to be accounted for. This was applicable both to consonants and vowels. For example, the Bangla word "বাক্য" (/bak-ko/ "sentence") has a complex grapheme sequence where /k/ is followed by /j/ in "ক্য;" but, the combination is not pronounced as [kj]; rather it appears as [kk] in speech. Therefore, the sequence $/ \mathrm{kj} /$ was required to be revised as / kk/ in the corpus. Also, Bangla orthography sometimes lack explicit vowel graphemes, but vowels are do appear in speech form. For example, the word "কবর" (/kobor/ "grave") has a sequence of three consonants only: /k, b, r/; but, two vowels appear in the speech form: [kobor]. Thompson (2012) called these 'inherent vowels' (p. 24) which always happen to be / $/$ / or /o/ depending on the phonological context.

A list of rules was developed and applied to convert the exceptional graphemes discussed above into the corresponding surfacing phonemes. This way, a phoneme dictionary was developed as a modified corpus which consisted of the words in Bangla orthography and their pronunciation as a sequence of phonemic segments.

\subsection{Analysis}

Nasal vowels in Bangla text are consistently marked with a diacritic called 'chandarabindu' (ّ) above the concerned segment, and this convention is almost exceptionless. Therefore, all the vowels having 'chandra-bindu' in the corpus were tagged as nasal vowels. For each of the word-types with a nasal vowel in it, the whole corpus was searched through to find (and record) any word of the same segments minus the nasal marker (essentially, minimal pairs). This process was repeated for all words for each vowel category. In case there were no minimal pairs for a vowel category, further investigations were performed by extracting the environments there occur in order to find and analyze near-minimal pairs.

The text processing and analyses were performed in Python and R (R Core Team, 2017). 


\section{Results}

\subsection{Vowel / /}

There were only 22 word-types with the nasal vowel / $\tilde{\partial} /$ in the whole corpus. And, interestingly enough, none of these words had any minimal or near-minimal pair in terms of nasal-oral difference. Some of the words with / ̃̃/ were, in fact, French names like /כ̃ri/ (Henry) and /mõlier/ (Moliere) which are often considered to have nasal vowels in the source language. This is an indication that the nasal vowel / $\tilde{z} /$ in these words are lexically inherent. The other words were the count words in Bangla. For

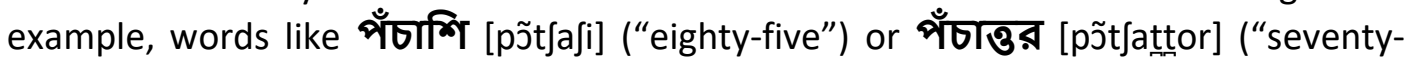
five") do have nasal vowels; but, the nasalization in / $/$ / is not contrastive with the oral counterpart. That is, the oral version [potfaji] is likely to be produced and perceived the same way as [p̃̃t]afi]. The vowels do not need to be faithful to being nasal which provides a complete optionality for the oral vowel to be nasal or not. This indicates that the nasal vowel may just be in free variation with the oral vowel.

\subsection{Vowel /æ/}

The corpus did not have any minimal or near-minimal pair for the vowel /æ/. In fact,

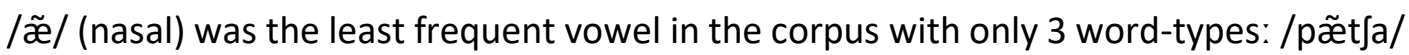
"owl", /pæ̃tfar/ "of owl", /pæ̃t]ano/ "to twist" (the first two belong to the same

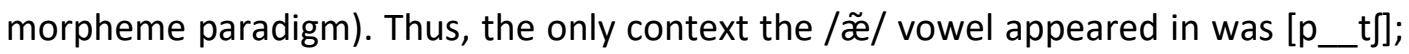
but, no words were found where the oral /æ/ appeared in the same context. Therefore,

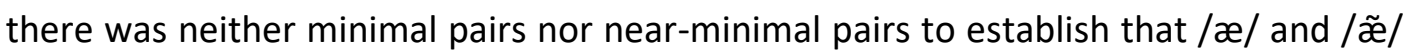
are in contrastive distribution in Bangla.

\subsection{Vowel /o/}

The corpus had 62 word-types that had nasal /õ/ in them; and there were indeed instances of true minimal pairs. As Table 4 shows, contrast in meaning is achieved based only on nasality differences between word pairs like $/ k^{h}$ õdza/ - $/ k^{h} \circ d z a /$, which is a clear indication that the nasal vowel is phonemically contrastive with the oral vowel.

Table 4: Minimal pairs for /õ/ vs. /o/

\begin{tabular}{|c|c|c|c|}
\hline With /õ/ & Gloss & With /o/ & Gloss \\
\hline /kñdza/ & to seek & $/ k^{h}$ odza/ & castrated \\
\hline /phõta/ & droplet (water) & $/ p^{\text {hotal }}$ & to bloom \\
\hline /gõra/ & bigoted & /gora/ & base \\
\hline /d $\mathrm{d}^{\mathrm{h}} \mathrm{o} a /$ & smoke & $/ d^{h} o a /$ & to wash \\
\hline
\end{tabular}


There were, however, some instances which posed a more complex scenario. The word / $\mathrm{t} \mathrm{h}^{\mathrm{h}} \mathrm{ora} /$ "to throw" can form a minimal pair with / $\mathrm{t} \int^{\mathrm{h}} \mathrm{o} \mathrm{ra} /$ if the intended meaning

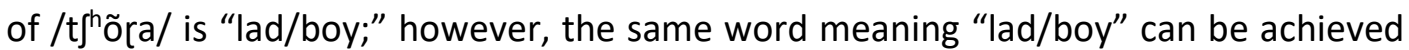
with the oral vowel too (/t $\int^{\text {h}}$ ora/) (Huq, Lahiri, \& Sarker, 2000, p. 446). Thus, the contrastiveness of /õ/ vs. /o/ is context dependent in such cases. Similar examples included /kñ̃ta-k hota/ "to mention someone's negative points," /khõpa-khopa/ "hair bun," /põța-pota/ "to plant/bury something in the ground," /phõra-phora/ "to pierce through something," etc. where nasality did not contribute to meaning differences indicating phonetic vairations.

\subsection{Vowel /u/}

There was a total of 827 word-types that had the nasal vowel /ũ/; and, there were only 4 minimal pairs based on /ũ/-/u/ contrast. Table 5 provides the list, which shows that lexical differences are caused by the difference of nasality alone in the vowel / $u /$; and, this works as a clear indication that /ũ/ is phonemically contrastive with / $\mathrm{u} / \mathrm{in}$ Bangla.

Table 5: Minimal pairs for /ũ/vs. /u/

\begin{tabular}{llll}
\hline With /ũ/ & Gloss & With /u/ & Gloss \\
\hline /kũri/ & bud & /kuri/ & twenty \\
/kũra/ & husk of paddy & $/$ kura/ & to collect from ground (2p.imp) \\
/kñuti/ & piller & $/ k^{\text {huti/ }}$ & to pick something up (1p) \\
/kũtfi/ & ruffle in dress & $/$ kut $\int i /$ & slices \\
\hline
\end{tabular}

Like the vowel /o/, the nasal /ũ/ was also found to be in free variation with an oral /u/, too. Table 6 lists such instances found in the corpus.

Table 6: Nasal vowels as phonetic variations in vowel /u/

\begin{tabular}{|c|c|}
\hline Word & Gloss \\
\hline /kũtfki/ or /kutfki/ & groin \\
\hline 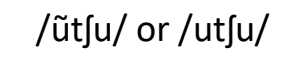 & high \\
\hline /d $\underline{d}^{h} \tilde{k} k$ / or / $d^{h} u k a /$ & to suffer \\
\hline$/ d^{h} \tilde{u} a /$ or $/ d^{h} u a /$ & smoke \\
\hline /pũtli/ or /putli/ & small bag \\
\hline$/ p u n t^{h_{i}} /$ or $/ p u t^{h_{i}} /$ & verse \\
\hline
\end{tabular}




\subsection{Vowel /i/}

In the /i/ vowel category, the corpus had 196 word-types that had the nasal/ĩ/in them; but, interestingly, none of these word-types had any counterpart minimally contrastive in terms of nasality. The corpus did have orthographic minimal pairs like /tĩra/ vs. $/ \mathrm{t}$ jita/ "flattened rice," but these were the variants of the same lexicon with the same meaning. Therefore, in the absence of true minimal pairs, it was necessary to look for near-minimal pairs.

Table 7 provides a subset of the near-minimal pairs for $/ \tilde{\mathrm{i}} /-\mathrm{i} / \mathrm{c}$ contrast in the corpus. As Table 7 indicates, the pairs are not exactly minimal pairs because they differ by more than one segment. But, the environments they two vowels (nasal vs. oral) occur are the same within pairs. For example, in /pĩpra/ "ant" and /pipaja/ "thirst," both /i// and /i/ occur in the same phonological environment $[\mathrm{p} \ldots \mathrm{p}]$; therefore, the positions of occurrence of the nasal and oral vowels are not predictable. This serves as an indication that these two vowels are in contrastive distribution.

Table 7: Near-minimal pairs for /ĩ/ vs. /i/

\begin{tabular}{|c|c|c|c|}
\hline With /Ĩ/ & Gloss & With /i/ & Gloss \\
\hline /Jĩdur/ & vermillion & /onfidar/ & partner \\
\hline$/ k^{n} \tilde{T} \mathrm{t} J /$ & to pull & $/ k^{h} i t \int u r i /$ & mixed rice \\
\hline /pĩpra/ & ant & /pipaJa/ & thirst \\
\hline /bĩdna & to drill & /bid ${ }^{\mathrm{h}} \mathrm{an} /$ & rules \\
\hline
\end{tabular}

\subsection{Vowel /e/}

The corpus had 478 word-types for the nasal vowel /ẽ/; however, only 4 minimal pairs could be established with the oral vowel (Table 8). All the other words with nasal /ẽ/ were either the phonetic variants or just inherently nasal vowels. Nevertheless, the minimal pairs in Table 7 provides evidence that nasality is still contrastive for vowel/e/.

Table 8: Minimal pairs for /ẽ/vs. /e/

\begin{tabular}{|c|c|c|c|}
\hline With /ũ/ & Gloss & With /u/ & Gloss \\
\hline /bẽtfe/ & to live & /betfe/ & to sell \\
\hline /kẽre/ & to mix & /kere/ & to snatch \\
\hline /gẽje/ & rural & /geje/ & to sing \\
\hline$/ \mathrm{t} \int^{\mathrm{h}} \mathrm{ẽ} \mathrm{re} /$ & to tear (3p) & $/ \mathrm{t} \int^{\mathrm{h}} \mathrm{ere} /$ & without \\
\hline
\end{tabular}




\subsection{Vowel /a/}

The occurrence of nasality was the highest for the vowel /a/ in the corpus with 2555 word-types. Of these, about 120 minimal pairs could be established (Table 9 provides a few examples). The nasal vowel/ã/, as Table 9 shows, clearly creates contrastive meaning from the oral vowel/a/generating minimal pairs, which is a solid evidence for /ã/ and /a/to create phonemic contrastiveness. This is consistent with the data from Thompson (2012) in Table 3.

Table 9: Minimal pairs for /ã/ vs. /a/

\begin{tabular}{llll}
\hline With /ũ/ & Gloss & With /u/ & Gloss \\
\hline /kãta/ & thorn & /kata/ & to cut \\
/bãd̆a/ & to tie & /badna/ $^{\text {ha }}$ & obstacle \\
/kãda/ & to cry & /kada/ & mud \\
/pãtha/ & goat & /patha/ & send (2P.Imp.) \\
\hline
\end{tabular}

\section{Conclusion}

This study concludes that nasality is phonemically contrastive for a subset of the seven oral vowels in Bangla, and not for all the vowels, as it has been consistently and widely claimed in existing literature. The evidence from minimal and near-minimal pairs from a Bangla corpus strongly suggests that only five $(/ \mathrm{i}, \mathrm{e}, \mathrm{a}, \mathrm{o}, \mathrm{u} / \mathrm{)}$ of the seven oral vowels have phonemically contrastive nasal counterparts. On the other hand, /æ/ and $/ \mathrm{J} /$ are argued to be not phonemically contrastive with their nasal counterparts / $\tilde{\gtrless} /$ and / $/ \tilde{J} /$ since the study could not find any evidence, in the forms of minimal or near-minimal pairs, to establish the claim. Therefore, the study suggests that nasality is not a phonemically contrastive feature for $/ æ /$ and $/ \mathrm{J} /$ in Bangla, and so, only five out of the seven Bangla monophthongs have contrastive nasal vowel counterparts.

It should be noted that the vowels participating in nasal contrastiveness may vary depending on the specific dialect of Bangla, as implicitly indicated by Khan (2008). This study focused on the Standard Colloquial Bangla, as used Bangladesh; reports from other dialects might be help in establishing a bigger picture of the vowel nasality scenario.

An interesting trend revealed in the study was that the frequency of nasal vowels in Bangla is very low in comparison to the oral ones; this is consistent with Sarkar's (2004) account of Bangla vowel frequency. Even more is the fact that many of the nasal vowels were, in fact, mere phonetic variation of the oral ones, and, therefore, did not contribute to any difference in lexical meaning. It might be possible that the variations 
are still conditioned by sociolinguistic factors. Along with this, it might also be an indication of diachronic changes in Bangla where contrasts based on nasality are diminishing; future studies should explore such possibilities.

\section{References}

Alam, F., Habib, S. M., \& Khan, M. (2008). Acoustic analysis of Bangla vowel inventory. Tech. rep. Center for Research on Bangla Language Processing; BRAC University. Retrieved on May 20, 2018, from http://citeseerx.ist.psu.edu/viewdoc/download?doi=10.1.1.173.651\&rep=rep1\&type=pdf

Arafat, Y., Islam, M. Z., \& Khan, M. (2006). Analysis and Observations from a Bangla news corpus. Proc. of 9th International Conference on Computer and Information Technology (ICCIT 2006), Dhaka, Bangladesh, December 2006.

Barman, B. (2011). A contrastive analysis of English and Bangla phonemics. Dhaka University Journal of Linguistics, 2(4), 19-42.

Basu, J., Basu, T., Mitra, M., \& Mandal, S. K. D. (2009). Grapheme to phoneme (g2p) conversion for Bangla. In Speech database and assessments, 2009 Oriental COCOSDA International Conference, 66-71. IEEE.

CMU Dict. (2018). The CMU pronouncing dictionary. Retrieved on June 10, 2018 from http://www.speech.cs.cmu.edu/cgi-bin/cmudict?in=C+M+U+Dictionary.

Huq, D. (2002). Bhasha Bigganer Katha [Facts about Linguistics]. Dhaka: Mowla Brothers.

Huq, M. E., Lahiri, S., \& Sarker, S. (2000). Bangla Academy Byabaharik Bangla Abhidhan [Bangla Academy Functional Bengali Dictionary]. Dhaka: Bangla Academy.

Kennedy, R. (2017). Phonology: A coursebook. Cambridge, UK: Cambridge University Press.

Khan, S. D. (2008). Intonational phonology and focus prosody of Bengali. UCLA Dissertation. Proquest UMI Dissertation Publishing.

Morshed, A. K. M. (1972). The phonological, morphological and syntactical patterns of standard colloquial Bengali and the Noakhali dialect. University of British Columbia MA thesis.

R Core Team. (2017). R: A language and environment for statistical computing. R Foundation for Statistical Computing Vienna, Austria. https://www.R-project.org/.

Sarkar, P. (2004). Segmental phonology of standard colloquial Bengali. University of Chicago, Department of Linguistics dissertation.

Shamim, A. (2011). A reanalysis of Bengali vowel assimilation with special attention to metaphony. The City University of New York, MA thesis.

Thompson, H. (2012). Bengali. Amsterdam, Philadelphia: John Benjamins Publishing Company.

Zsiga, E. C. (2013). The sounds of language: An introduction to phonetics and phonology. Oxford, Massachusetts: John Wiley \& Sons. 